\title{
An evaluation of the monophyly of Massarina based on ribosomal DNA sequences
}

\author{
Edward C. Y. Liew \\ Centre for Research in Fungal Diversity, Department of \\ Ecology $\mathcal{E}^{2}$ Biodiversity, The University of Hong Kong, \\ Pokfulam Road, Hong Kong SAR, PR China \\ André Aptroot \\ Centraalbureau voor Schimmelcultures, P.O. Box \\ 85167, NL-3508 AD Utrecht, The Netherlands \\ Kevin D. Hyde ${ }^{1}$ \\ Centre for Research in Fungal Diversity, Department of \\ Ecology $\mathcal{E}$ B Biodiversity, The University of Hong Kong, \\ Pokfulam Road, Hong Kong SAR, PR China
}

\begin{abstract}
The monophyletic status of the genus Massarina was evaluated on the basis of phylogenetic analysis of the partial small subunit gene (SSU), internal transcribed spacers (ITS $1 \& 2$ ), and 5.8S gene sequences of the ribosomal DNA. Species of Massarina used in the study clustered into two distinct clades with high bootstrap support in trees generated from maximum parsimony, weighted parsimony, maximum likelihood, and neighbor-joining analyses. The hypothesis that Massarina species belong to a phylogenetically monophyletic group is rejected. Species with narrowly fusiform ascospores form a monophyletic clade with Lophiostoma, a genus highly similar in morphology. The five species currently accepted in Massarina with such spore morphology are here transferred into the genus Lophiostoma. Massarina species with broadly fusiform to ellipsoidal ascospores are retained as Massarina s. str., lectotypified by M. eburnea. Massarina walkeri is presently excluded from both Massarina and Lophiostoma. The transfer of M. papulosa to a new genus Oletheriostrigula is verified.
\end{abstract}

Key Words: ascomycetes, fungi, Lophiostoma, Lophiostomataceae

\section{INTRODUCTION}

Massarina Sacc. was introduced by Saccardo (1883) for species of pyrenocarpous ascomycetes that had previously been placed in Massaria De Not. but typically had hyaline ascospores (Bose 1961). Eleven spe-

Accepted for publication February 20, 2002.

${ }^{1}$ Corresponding author, Email: kdhyde@hkucc.hku.hk cies were included in Massarina, the first being Massarina eburnea (Tul. \& C. Tul.) Sacc., but a type was not indicated, nor was the genus placed in a family. Massarina eburnea was later selected as lectotype of this genus by Clements and Shear (1957) and was redescribed and illustrated by Hyde (1995a).

A new family, the Massarinaceae Munk, was introduced by Munk (1956) to accommodate Massarina. This family was accepted by various authors (Eriksson 1981, 1982, Eriksson and Hawksworth 1985). Bose (1961), in his review of Massarina, noted that doubts had previously been expressed several times about whether the introduction of a new family was justified (Holm et al 1957, Scheinpflug 1958). He subsequently placed Massarina in the existing Pleosporaceae, due to the lack of distinctive characters distinguishing the two families. This placement was supported by some authors (Müller and von Arx 1962, Luttrell 1973, von Arx and Müller 1975), but Massarina was eventually disposed within the Lophiostomataceae Sacc. in the Pleosporales (Eriksson and Yue 1986, Barr 1987, 1992).

Since Saccardo's initial inclusion of 11 species in Massarina, numerous species have been described in or transferred to this genus. Bose (1961) discussed 19 species in his review, which covered mostly the European species. Srinivasulu and Sathe (1974) covered nine species from India, while Barr (1992) treated the North American members of the genus. None of these revisions were exhaustive. A list of 132 species described in Massarina was annotated by Hyde (1995a). More recently, many new species have been described: five from marine or mangrove intertidal environments (Hyde and Borse 1986, Kohlmeyer and Volkmann-Kohlmeyer 1987, Hyde 1989, 1991, Hyde et al 1992), eight from the freshwater environment (Hyde 1992, 1994, 1995b, Shearer and Hyde 1997, Hyde and Aptroot 1998, Tsui et al 1999a), and eight from terrestrial environments (Shoemaker et al 1991, Hyde and Aptroot 1997, Poonyth et al 1999, Aptroot et al 2000).

In response to an obvious need to revise all previously described species including those from the tropics, Aptroot (1998) published a world revision of the genus Massarina and accepted 43 species. All of these species are characterized by cellular pseudoparaphyses, hyaline, septate, fusiform to long-ellip- 
soidal ascospores and bitunicate asci. Massarina eburnea has an immersed, poorly developed ascoma wall and broadly fusiform, 3-septate ascospores with a thick gelatinous sheath. The majority of the species differ from the type species in various characters, especially in regard to the ascospore shape, which is often narrowly fusiform, and to the shape and extension of the gelatinous sheath around the ascospores.

Aptroot (1998) commented that the accepted species of Massarina probably do not form a monophyletic group. Some species are similar to other genera, differing in very few characters, and some of the reported anamorphs suggest very different groups. Subdivisions within this genus were however not made, mainly because of the uncertainty in selecting the appropriate delineating morphological characters. Aptroot (1998) pointed out the need for examining characters of different levels, ultrastructural and molecular. Several reports of ultrastructural examination of Massarina species have not only confirmed and clarified observations based on light microscopy, but have revealed structures that could not be resolved by light microscopy (Read et al 1994, 1997, Tsui et al 1999b). Ultrastructural examinations generally reveal consistent structures in all the Massarina species examined, except for the occasional appearance of ascospore polar chambers formed from the episporial cell wall layer, and of lateral, fibrillar appendage-like structures. Polar chambers have been observed in taxonomically distinct groups of marine ascomycetes and seem to have developed independently in several evolutionary lineages (Read et al 1997). Such convergent characters are not considered to be of primary taxonomic importance.

In evaluating the phylogenetic significance of pseudoparaphyses in the loculoascomycetes, Liew et al (2000) included three Massarina species in their $18 \mathrm{~S}$ subunit ribosomal DNA analysis. These species did not form a monophyletic group. Massarina australiensis and $M$. bipolaris clustered together with $L^{-}$ phiostoma caulium, away from M. eburnea. Morphologically, some Massarina species are remarkably similar to Lophiostoma, which differs in its laterally compressed slot-like ascomatal ostioles (Eriksson and Yue 1986, Hyde 1995a, Aptroot 1998, Hyde and Aptroot 1998).

The current research aimed to assess the monophyly of the genus Massarina by phylogenetic analysis of the ribosomal DNA. First, sequences of $5.8 \mathrm{~S}$ gene and internal transcribed spacer (ITS) regions were analyzed in combination with previously published $18 \mathrm{~S}$ small subunit (SSU) sequences. Subsequently, sequences of $5.8 \mathrm{~S}$ and ITS regions from a larger sample size of Massarina species and members of closely related genera were analyzed.

\section{MATERIALS AND METHODS}

Cultures and DNA sequences.-The sources of fungal cultures and GenBank sequences used in the study are listed in TABLE I. Identification of fungal specimens was verified based on morphological characters before a single spore culture was obtained and cultured on cornmeal agar, (CMA [Difco]). Cultures from the Centraalbureau of Schimmelcultures (CBS, Utrecht) were purified by subculturing from a single hyphal tip onto the culture medium recommended for the respective strain by CBS. All cultures were subcultured onto V8 agar (40\% Campbell V8 Juice) for rapid growth 1-2 w prior to DNA extraction.

DNA extraction.-Actively growing mycelia were directly scraped off from culture plates and transferred into $1.5 \mathrm{~mL}$. centrifuge tubes. DNA extraction followed a modified protocol of Doyle and Doyle (1987). Approximately $0.05 \mathrm{~g}$ of mycelium was mixed with ca $0.3 \mathrm{~g}$ of white quartz sand (Sigma) in warm (ca $60 \mathrm{C}) 2 \times \mathrm{CTAB}$ buffer $[2 \%(\mathrm{w} / \mathrm{v}) \mathrm{CTAB}$; $100 \mathrm{mM}$ Tris-HCl; $1.4 \mathrm{M} \mathrm{NaCl} ; 20 \mathrm{mM}$ EDTA, pH 8.0]. Mycelium-sand mixture was ground with a glass pestle and incubated at $60 \mathrm{C}$ for $1 \mathrm{hr}$ before being subjected to multiple phenol:chloroform (1:1) extractions. DNA was precipitated from the purified aqueous extraction layer by ethanol precipitation. The DNA pellet was washed (70\% ethanol), dried (vacuum centrifuge) and resuspended in $100 \mu \mathrm{L} \mathrm{TE}$ buffer containing $0.8 \mu \mathrm{g} / \mathrm{mL}$ of RNase A (Sigma). DNA samples were checked for purity and integrity by gel electrophoresis before storing at $4 \mathrm{C}$.

DNA fragment amplification.-The ITS 1, 5.8S gene and ITS 2 of the rDNA was amplified using primers ITS4 and ITS5 (White et al 1990). Two to $5 \mu \mathrm{L}$ of suspended DNA were used for each polymerase chain reaction (PCR) with 1.5 $\mathrm{mM} \mathrm{MgCl} 2,0.2 \mathrm{mM}$ of each dNTP, $0.3 \mu \mathrm{M}$ of each primer, and $2.0 \mathrm{U}$ of Taq DNA polymerase in a $50 \mu \mathrm{L}$ reaction volume. The thermal cycling program was as outlined in White et al (1990), with primer annealing at 52 C for $50 \mathrm{~s}$. The size of each amplified fragment was verified by gel electrophoresis with ethidium bromide staining of a $2 \mu \mathrm{L}$ product sample and visualized over an ultraviolet transilluminator. PCR products were purified using the Wizard PCR Preps DNA Purification System (Promega) and the purified products were further assessed for purity and sufficiency in concentration by gel electrophoresis (using $0.5 \mu \mathrm{L}$ ). Where necessary, fragment suspensions were further concentrated in a vacuum centrifuge, and stored for not more than $1 \mathrm{wk}$ before DNA sequencing.

DNA sequencing.-The amplified DNA fragments were directly sequenced using the ALFexpress Automated DNA Sequencer AM V 3.0 (Pharmacia Biotech). Sequencing reactions were conducted in a thermal cycler using the Auto Cycle 200 Sequencing Kit (Pharmacia) according to the manufacturer's recommendations. CY-5 labelled primers ITS2, ITS3, ITS4, and ITS5 (White et al 1990) were used, which allowed for the determination of both DNA strands. The optimal annealing temperature for each primer used in the sequencing reaction was empirically determined taking into consideration the calculated temperature based on the manufacturer's instructions for the Sequencing Kit. 
TABLE I. Fungal species and strains used in the study and their rDNA GenBank accession numbers

\begin{tabular}{|c|c|c|}
\hline Species and strain & $\begin{array}{l}\text { Source of } \\
\text { culture }\end{array}$ & GenBank accession no. \\
\hline Botryosphaeria quercuum (Schw. : Fr.) Sacc. & CBS 177.89 & AF164352a,$A F 383949^{b}$ \\
\hline Botryosphaeria sp. & HKUCC 126 & AF $383950^{\mathrm{b}}$ \\
\hline Leptospora rubella (Pers. : Fr.) Rabenh. & CBS 132.80 & $\mathrm{AF} 164361^{\mathrm{a}}, \mathrm{AF} 83951^{\mathrm{b}}$ \\
\hline \multicolumn{3}{|l|}{ Lophiostoma arundinis (Pers. : Fr.) } \\
\hline Ces. \& De Not. & CBS 621.86 & AF164362a, AF383952b \\
\hline Lophiostoma caulium (Fr.) Ces. \& De Not. & CBS 624.86 & AF383953b \\
\hline Lophiostoma vagabundum Sacc. & CBS 628.86 & AF383954 \\
\hline \multicolumn{3}{|l|}{ Massarina armatispora K.D Hyde, Vrijmoed, } \\
\hline Chinnarij \& E.G.B. Jones & HKUCC 1562 & AF383955 \\
\hline Massarina bipolaris K.D. Hyde & HKUCC 1053 & AF164365 ${ }^{\mathrm{a}}, \mathrm{AF} 383956^{\mathrm{b}}$ \\
\hline Massarina corticola (Fuckel) L. Holm & CBS 154.93 & AF383957b \\
\hline Massarina eburnea 1 (Tul. \& Tul.) Sacc. & HKUCC 4054 & AF164366 ${ }^{\mathrm{a}}, \mathrm{AF} 383958^{\mathrm{b}}$ \\
\hline Massarina eburnea 2 (Tul. \& Tul.) Sacc. & CBS 473.64 & $\mathrm{AF} 164367^{\mathrm{a}}, \mathrm{AF} 383959^{\mathrm{b}}$ \\
\hline Massarina fronsisubmersa K.D. Hyde & $\mathrm{HKU}(\mathrm{M}) 4685$ & AF383960 \\
\hline \multicolumn{3}{|l|}{ Massarina papulosa (Durieu \& Montagne) } \\
\hline \multicolumn{3}{|l|}{ S.K. Bose \{Oletheriostrigula papulosa (Durieu \& Mont.) } \\
\hline S.M. Huhndorf \& R.C. Harris\} & CBS 471.64 & AF383961 ${ }^{b}$ \\
\hline Massarina ramunculicola K.D. Hyde & HKUCC 6422 & AF383962 ${ }^{\mathrm{b}}$ \\
\hline Massarina rubi (Fuckel) Sacc. & CBS 691.95 & AF383963 ${ }^{\mathrm{b}}$ \\
\hline Massarina thalassiae Kohlm. \& Volkm.-Kohlm. & HKUCC 642 & AF383964 \\
\hline Massarina walkeri Shoemaker, C.E. Babc. \& J.A.G. Irwin & CBS 257.93 & AF383965 \\
\hline Montagnula opulenta (De Not.) Aptroot & CBS 168.34 & AF $164370^{\mathrm{a}}, \mathrm{AF} 383966^{\mathrm{b}}$ \\
\hline Pleospora herbarum (Fr.) Rabenh. ex Ces. \& De Not. & CBS 191.86 & $\mathrm{U} 05201^{\mathrm{a}}, \mathrm{AF} 383967^{9}$ \\
\hline Vaginatispora aquatica K.D. Hyde & HKUCC 164 & AF383968 b \\
\hline Wettsteinina lacustris (Fuckel) Shoemaker \& C.E. Babc. & CBS 618.86 & AF383969 \\
\hline
\end{tabular}

a Partial sequence of rDNA $18 \mathrm{~S}$ small subunit.

b Sequence of rDNA ITS1-5.8S-ITS2 region.

Sequence alignment.-For each fungal strain, four separate sequences obtained for the respective primers were manually aligned and spliced to obtain a consensus sequence using the biosequence editor SeqPup v0.8 (Gilbert 1998). During this process of alignment, individual bases were verified by comparison with the fluorescence signal printout for each sequence. Consensus sequences for each strain, together with the sequences obtained from GenBank, were aligned using ClustalX (Thompson et al 1994). The result was further adjusted manually to allow for maximum alignment. Gaps were always coded as missing data. Regions where alignment was ambiguous due to the large number of gaps were deleted from the analysis. The ITS- $5.8 \mathrm{~S}$ data were also combined with selected SSU sequences from Liew et al (2000) (where identical strains were used) to form a single data set. The alignment data sets are available from TreeBASE (SN840-2325, SN840-2326).

Phylogenetic analysis.-All phylogenetic analyses were performed using PAUP*4.0b8 (Swofford 1998). The ITS-5.8S data set was subjected to analyses based on different criteria: maximum parsimony (MP), weighted parsimony (WP), maximum likelihood (ML) and neighbor-joining (NJ). Only the maximum parsimony criterion was used for the combined SSU and ITS- $5.8 \mathrm{~S}$ data set. For the combined SSU and ITS-5.8S data set, a partition homogeneity test (PHT) was implemented in PAUP* using 1000 replicates to evalu- ate combinability of the two separate DNA regions. All parsimonious trees were generated by heuristic searches with tree-bisection-reconnection (TBR) as the branch swapping algorithm, gaps as missing data, with 1000 replications of random stepwise sequence addition, and branches collapsed if maximum branch length was zero, with the MULPARS option in effect. For MP analysis, a transition : transversion (ts : tv) ratio of 1 was used, while ratios of 1.5 and 2.0 were used for the WP analysis. The estimated ts:tv ratio was 1.99 (ML analysis below). Topological constraints for monophyly were enforced on various combinations of Massarina species: MassMonoA (all Massarina species studied were constrained to form a monophyletic clade); MassMonoB (all Massarina species except M. papulosa \{as Oletheriostrigula papulosa (Durieu \& Mont.) S.M. Huhndorf \& R.C. Harris\} were constrained to form a monophyletic clade); and MassMonoC (all Massarina species except $M$. papulosa \{Oletheriostrigula papulosa\} and $M$. walkeri were constrained to form a monophyletic clade). These constrained topologies were then subjected to heuristic searches for the maximally parsimonious trees.

The ML tree was generated from a heuristic search using base frequencies, ts : tv ratio, rates of change of sites estimated from one of the most parsimonious trees generated in the MP analysis, based on the HKY85 model (Hasegawa et al 1985). The NJ tree was generated based on the Kimura 
2-Parameter, K2P (Kimura 1980), JC (Jukes and Cantor 1969), and F84 (Felsenstein 1984) distance measures, using parameters as estimated for the ML analysis. All trees were rooted by outgroup rooting with either one or both of Botryosphaeria quercuum and Botryosphaeria sp. These outgroup taxa were chosen on the basis of their position as sister taxa to Pleosporales (Liew et al 2000), their appropriate phylogenetic distance from Massarina and allied genera for analysis of both conserved (SSU and 5.8S) and variable (ITS) regions of the rDNA, and the availability of sequence data. Tree lengths, consistency and retention indices, and In-likelihoods of tree topologies generated from various analyses with various conditions and parameters were generated. Significance of difference in tree lengths and ln-likelihoods was statistically evaluated by the KishinoHasegawa test (KHT, Kishino and Hasegawa 1989) using default likelihood settings. The combined SSU and ITS-5.8S was subjected to a partition homogeneity test, implemented using 1000 replicates, in order to determine the combinality of the separate DNA regions. Statistical support for branching nodes was assessed by bootstrap analysis with bootstrapping replicates (1000 for the MP and NJ trees and 500 for the ML tree) of the aligned data set.

\section{RESULTS}

The combined SSU and ITS-5.8S aligned data set of eight strains comprised 1774 characters, of which 317 were parsimony-informative (TreeBase SN840-2325). Results from the PHT of this combined data set indicated that the two separate regions within the ribosomal DNA were highly congruent $(p=0.06)$, justifying the combined data analysis. PHT p-values of greater than 0.01 generally indicate a level of congruence between data sets, which when combined will provide more confident phylogenetic inferences from the data (Cunningham 1997). A single MP tree was generated from the heuristic search (FIG. 1) with a length of 888 steps and consistency and retention indices of 0.843 and 0.764 , respectively. The tree shows two distinct monophyletic clades with high bootstrap support $(>80 \%)$ : one with Massarina bipolaris clustering together with Lophiostoma caulium, and the other comprising Massarina eburnea (the lectotype of the genus) together with Montagnula opulenta. Pleospora herbarum and Leptospora rubella form a sister group with the latter clade. Species of Massarina included in this analysis do not form a phylogenetically monophyletic group.

The ITS-5.8S data set of a larger sampling size with 21 strains, including more representatives of Massarina and other closely related genera, yielded 721 characters, of which 374 were parsimony-informative (SN840-2326). Non-weighted MP analysis of this data set yielded two equally most-parsimonious trees of 1621 steps in length, and with consistency and retention indices of 0.597 and 0.606 , respectively. FIGURE
2 shows the tree with the higher In-likelihood (-Ln = 7689.19232). Other than M. papulosa (Oletheriostrigula papulosa) and M. walkeri, species of Massari$n a$ clustered together into two well-supported main clades. Massarina bipolaris, $M$. fronsisubmersa, M. corticola, M. armatispora, and M. rubi grouped together with species of Lophiostoma and Vaginatispora to form one clade with a bootstrap support of $85 \%$, while $M$. eburnea, M. ramunculicola, and M. thalassiae formed another Massarina clade with $80 \%$ bootstrap support. Massarina walkeri clustered with Pleospora herbarum and Leptospora rubella with $89 \%$ bootstrap support, forming a sister group to the M. eburnea clade. Massarina papulosa, however, is distantly positioned from the two main clades of Massarina species (with a bootstrap support of $100 \%$ ). The topology of the other equally most parsimonious tree concurrently generated $(-\mathrm{Ln}=7691.37005)$ is identical with the exception that $M$. corticola formed a cluster with $M$. bipolaris and $M$. fronsisubmersa (data not shown).

Weighted Parsimony (WP) analyses were performed to evaluate tree topologies generated using various ts : tv ratios. TABLE II shows the different statistics of trees obtained from WP analyses using ts: tv ratios of $1.0(\mathrm{MP}), 1.5$ and 2 . A single most parsimonious tree was obtained for ts : tv ratios of 1.5. Its topology was identical to one of the equally mostparsimonious trees in MP (non-weighted) analysis (FIG. 2). When a ratio of 2 was used, two equally most parsimonious trees were obtained and these were identical in topology to the two trees obtained for the MP analysis. Trees from both WP analyses were longer than the MP trees and had lower consistency and retention indices. No significant differences were observed in ln-likelihood.

To further evaluate the monophyly of the genus Massarina, constrained trees were generated with topological constraints forcing specified species of Massarina into monophyletic groups. Lengths, consistency and retention indices, and ln-likelihood values of these trees are shown in TABLE III. The significance of differences in tree lengths and ln-likelihoods, as evaluated by the Kishino-Hasegawa test, is also shown. All constrained trees forcing species of Massarina, including or excluding M. papulosa (Oletheriostrigula papulosa) and/or M. walkeri, were significantly longer in length and lower in ln-likelihood values. In addition, the level of homoplasy in these trees was increased as indicated by the lower consistency and retention indices.

The ML tree generated using the estimated parameters (tv: ts, base frequencies, and site rate variations) was identical in topology to FIG. 2, with no significant difference in ln-likelihood or tree length (data not shown). The NJ trees generated using var- 


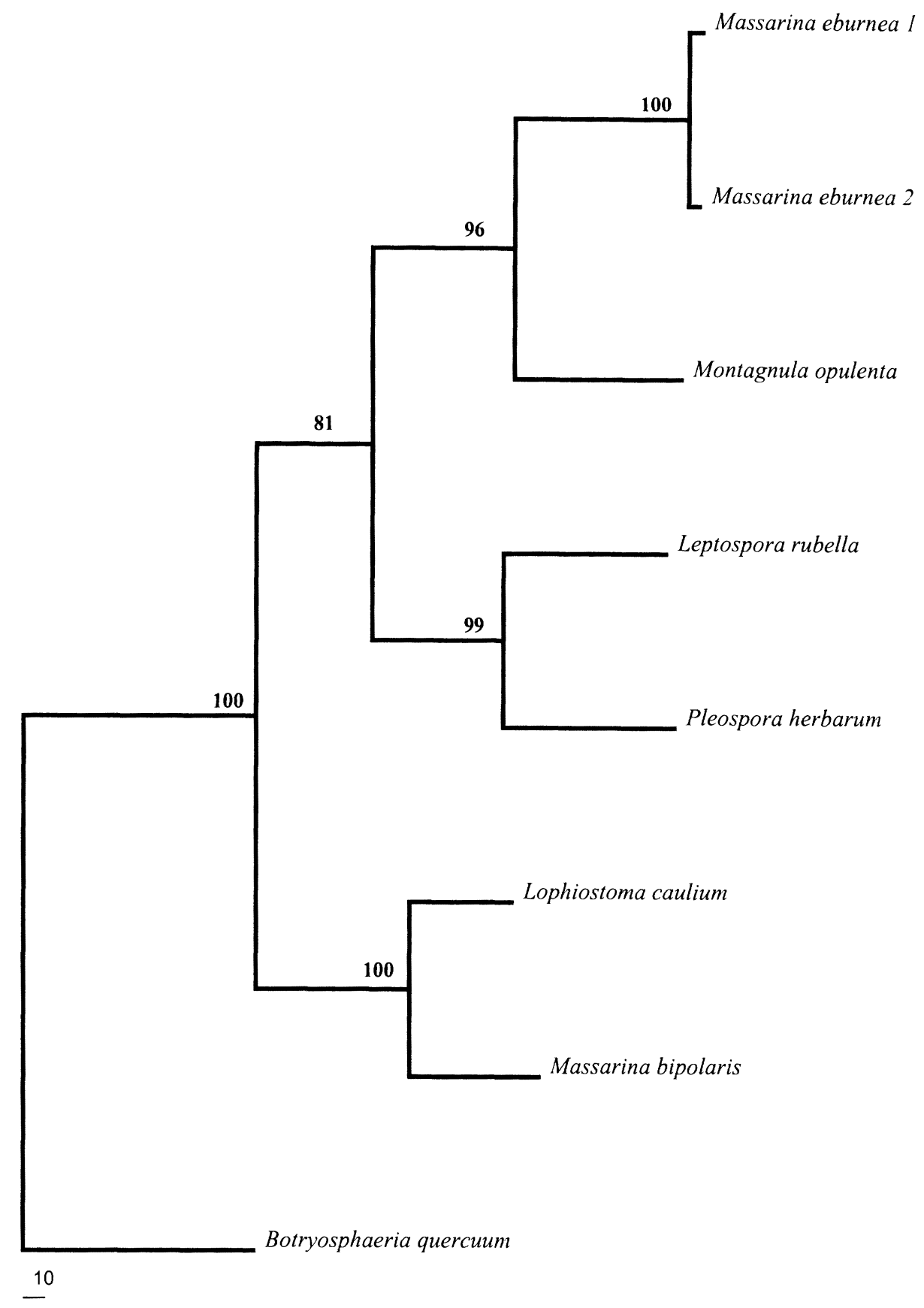

FIG. 1. Single most parsimonious tree obtained from combined SSU and ITS-5.8S data set. Branching node confidence values above $50 \%$, calculated using 1000 replicates from heuristic search of parsimony-informative characters, are shown above the nodes. Length $=888$ steps; $\mathrm{CI}=0.843 ; \mathrm{RI}=0.764$.

ious distance measures yielded trees of the same topology. Figure 3 shows the NJ tree generated using the K2P distance measure. This NJ tree is slightly longer in steps and lower in ln-likelihood but not significantly different from the best MP tree (KHT results not shown). The consistency and retention indices were also slightly lower. Although differences in tree topology were observed, the two main clades comprising the Massarina species again appeared as in the MP trees, with M. papulosa (Oletheriostrigula pa- pulosa) again clustering away in isolation. M. walkeri grouped with Pleospora herbarum and Leptospora rubella as in the MP trees, indicating a distant relationship with the M. eburnea clade.

\section{DISCUSSION}

The main purpose of this study was to evaluate the monophyly of the genus Massarina. Several authors, notably Aptroot (1998), commented that the genus 


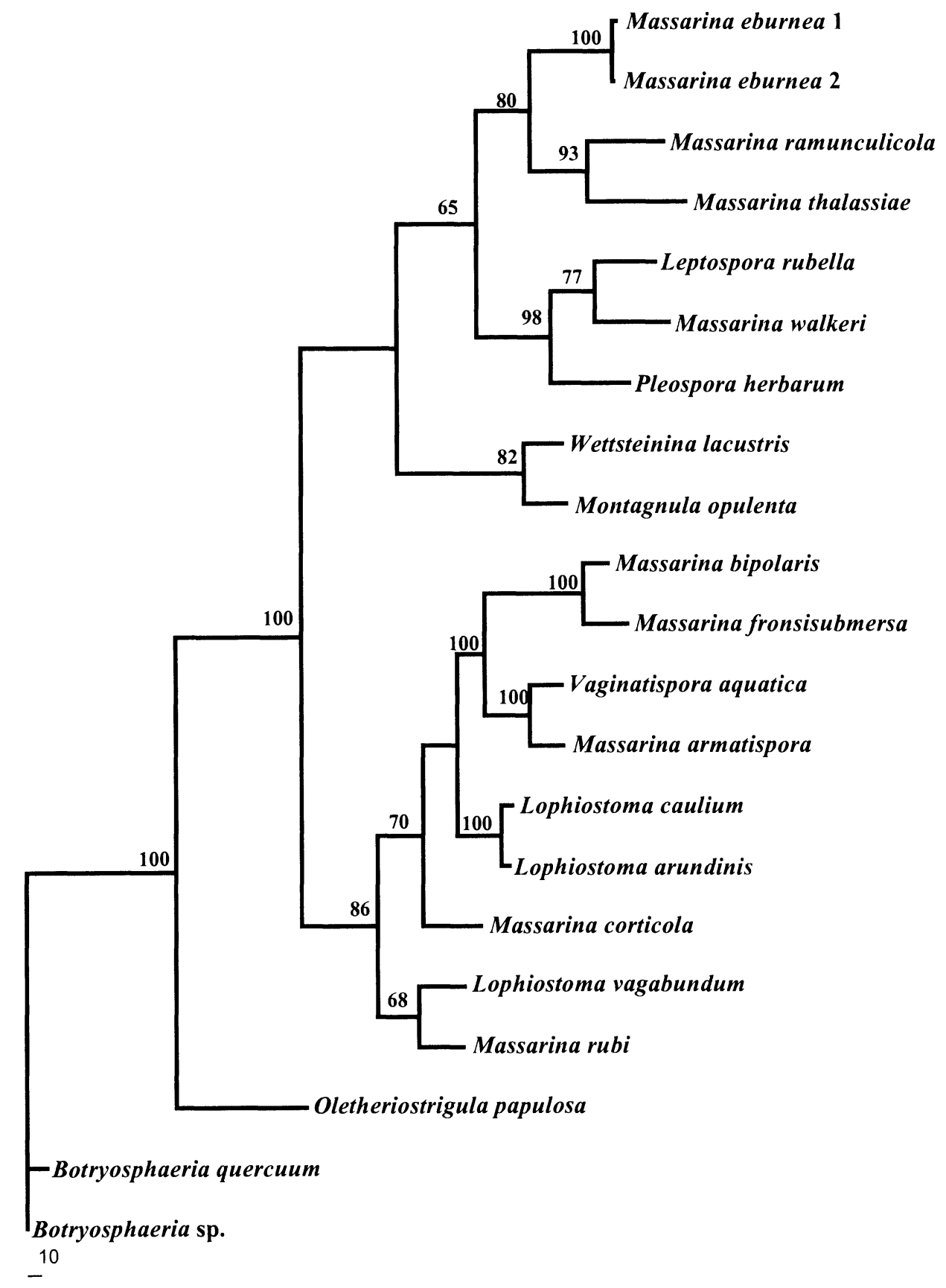

FIG. 2. Best $(-\ln$ L) of 2 equally most parsimonious trees generated from a heuristic search with 1000 replicates of random stepwise sequence addition with TBR based on the ITS-5.8S data. Numbers above branching nodes denote the bootstrap values from 1000 replicate-heuristic search on all parsimony-informative characters. Length $=1621 ; \mathrm{CI}=0.597$; $\mathrm{RI}=0.606$.

is heterogeneous and phylogenetically most probably not monophyletic. No attempts were made previously to separate this genus due to the lack of evidence for any appropriate delineating characters. The results generated in our study reveal that the current definition of Massarina is not monophyletic.

Combined SSU and ITS-5.8S analysis of a limited number of Massarina and related species confirmed a previous work, based solely on SSU sequences, that suggested there were at least two major phylogenetic groups within the genus (Liew et al 2000). In the present study, analyses of ITS-5.8S sequences from a larger sample of Massarina and related species further corroborated the conclusion. Analyses whereby topological constraints were imposed, in various combinations, forcing the monophyly of Massarina species, clearly rejected the hypothesis that the genus was monophyletic. In all the trees obtained from 
TABLE II. Statistics of trees obtained using MP and WP analyses, and results of Kishino-Hasegawa test on the differences in ln-likelihood

\begin{tabular}{lcccccc}
\hline \hline Criterion & Tree \# & Length (steps) & CI & RI & - ln L & P \\
\hline MP & 1 & 1621 & 0.597 & 0.606 & 7691.37005 & 0.8418 \\
& 2 & 1621 & 0.597 & 0.606 & 7689.19232 & Best \\
WP 1.5 & 1 & 1993.4 & 0.571 & 0.598 & 7689.19232 & 1.0000 \\
WP 2.0 & 1 & 2552 & 0.546 & 0.591 & 7689.19232 & 1.0000 \\
& 2 & 2552 & 0.546 & 0.591 & 7696.04663 & 0.4313 \\
\hline
\end{tabular}

aProbability of getting a more extreme T-value under the null hypothesis of no difference between the two trees (twotailed test) with significance at $P<0.05$.

b Transition : transversion ratio of 1.5 or 2.0 .

analyses conducted using various optimality criteria and phylogenetic parameters, a major bifurcation of Massarina species was clearly shown. The clade with the type species, M. eburnea, also includes other species with broadly fusiform to ellipsoidal ascospores. The other clade consists of species with narrowly fusiform ascospores, which clustered together with all taxa from the Lophiostomataceae.

The current morphological circumscription of Massarina is narrowly specified except in relation to ascospore size, shape, and sheath morphology. The generic description includes ascospores ranging from fusiform to broadly ellipsoidal, while the ascospore sheath may be absent, thin, and following the outlines of the ascospore, or ornamented with appendices of various shapes (Hyde 1995a, Aptroot 1998). Massarina is remarkably similar to Lophiostoma, the main differentiating characters being the slot-like ostioles and the 'lophiostomoid' (with large cells in the corners in vertical section) peridium often but not always present in Lophiostoma. Holm and Holm (1988) considered the slot-like ostiole in the Lophios- tomataceae to be an unstable and highly adaptive character. Eriksson and Yue (1986) also noted the similarity between the two genera and recommended a study of the whole group in order to redefine generic delineations. With reference to the ascomal characters of Massarina species used in the present study, both $M$. eburnea and $M$. ramunculicola have very short ostiolar necks (ca $50 \mu \mathrm{m}$ ), while that of M. thalassiae is slightly longer $(70-100 \mu \mathrm{m})$ (Kohlmeyer and Volkmann-Kohlmeyer 1987, Hyde 1995a, 1991). On the other hand, Massarina armatispora, $M$. fronsisubmersa and Vaginatispora aquatica all possess much longer ostiolar necks (100-200 $\mu \mathrm{m})$, which are slightly compressed, resembling the slot-like ostioles of Lophiostoma species (Hyde 1994, 1995c, Hyde et al 1992). However, this character does not appear to be phylogenetically consistent in that not all of the Massarina species in the Lophiostoma clade possess such long compressed ostiolar necks. Furthermore, both $M$. bipolaris and Vaginatispora aquatica produced ascomata of different shapes when grown in vitro. On artificial medium, the ascoma of M. bipo-

TABLE III. Statistics of trees obtained from MP analyses with various topological constraints, and results of Kishino-Hasegawa test on the differences in length and ln-likelihood

\begin{tabular}{|c|c|c|c|c|c|c|c|}
\hline Topologyc & Tree \# & $\begin{array}{l}\text { Length } \\
\text { (steps) }\end{array}$ & $\mathrm{P}^{\mathrm{a}}$ & CI & RI & $-\ln \mathrm{L}$ & $\mathrm{Pa}^{\mathrm{a}}$ \\
\hline \multirow[t]{2}{*}{ Unconstrained } & 1 & 1621 & Best & 0.597 & 0.606 & 7691.37005 & 0.8418 \\
\hline & 2 & 1621 & 1.0000 & 0.597 & 0.606 & 7689.19232 & Best \\
\hline \multirow[t]{2}{*}{ MassMonoA } & 1 & 1748 & $<0.0001^{\mathrm{b}}$ & 0.553 & 0.530 & 7975.48392 & $<0.0001^{\mathrm{b}}$ \\
\hline & 2 & 1748 & $<0.0001^{\mathrm{b}}$ & 0.553 & 0.530 & 7975.48392 & $<0.0001^{\mathrm{b}}$ \\
\hline \multirow[t]{4}{*}{ MassMonoB } & 1 & 1699 & $<0.0001^{\mathrm{b}}$ & 0.569 & 0.560 & 7902.23483 & $<0.0001^{\mathrm{b}}$ \\
\hline & 2 & 1699 & $<0.0001^{b}$ & 0.569 & 0.560 & 7902.23483 & $<0.0001^{\mathrm{b}}$ \\
\hline & 3 & 1699 & $<0.0001^{\mathrm{b}}$ & 0.569 & 0.560 & 7902.26211 & $<0.0001^{\mathrm{b}}$ \\
\hline & 4 & 1699 & $<0.0001^{\mathrm{b}}$ & 0.569 & 0.560 & 7902.26211 & $<0.0001^{\mathrm{b}}$ \\
\hline \multirow[t]{2}{*}{ MassMonoC } & 1 & 1674 & $<0.0001^{\mathrm{b}}$ & 0.578 & 0.575 & 7830.02573 & $<0.0001^{\mathrm{b}}$ \\
\hline & 2 & 1674 & $<0.0001^{\mathrm{b}}$ & 0.578 & 0.575 & 7832.70582 & $<0.0001^{\mathrm{b}}$ \\
\hline
\end{tabular}

\footnotetext{
tailed test) with significance at $P<0.05$.

${ }^{\mathrm{b}}$ Significant P-values as determined by the two-tailed test.

c Various topological constraints as described in the Materials and Methods section.
}

a Probability of getting a more extreme T-value under the null hypothesis of no difference between the two trees (two- 


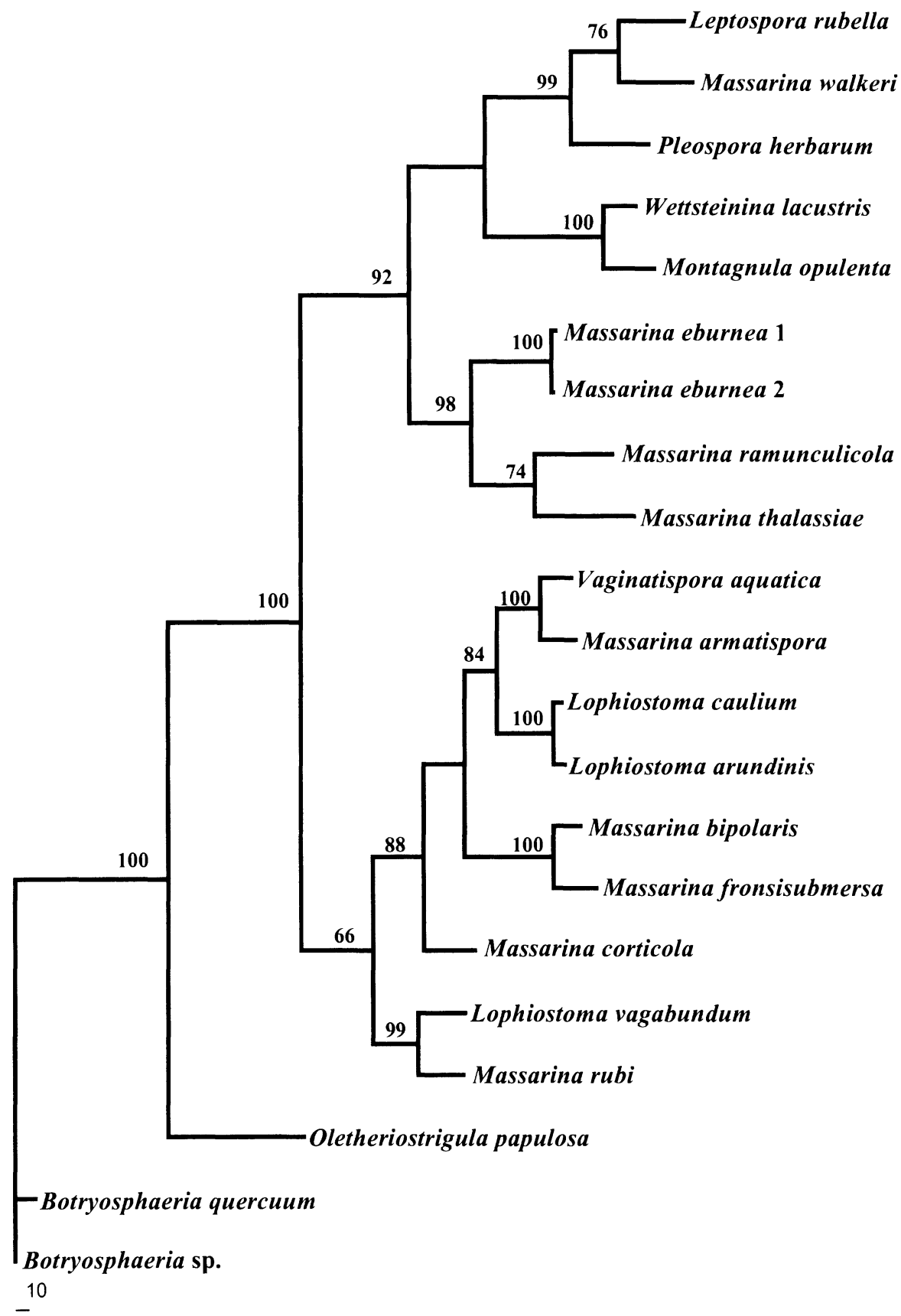

FIG. 3. Neighbor-joining tree generated from the ITS-5.8S data based on the K2P distance measure. Branching node confidence values above $50 \%$, calculated using 1000 replicates from heuristic search of parsimony-informative characters, are shown above the nodes. Length $=1629 ; \mathrm{CI}=0.594 ; \mathrm{RI}=0.602 ;-\ln \mathrm{L}=7697.77925$.

laris appears to be long-necked (ca $200 \mu \mathrm{m}$ ) and conical with rounded base in cross-section, but on wood, it is short-necked (ca $100 \mu \mathrm{m}$ ) and ellipsoidal with a flattened base in cross-section (Hyde 1995b). Similarly, although the ascoma of Vaginatispora aquatica has a compressed slot-like ostiole on natural substrate, it has a rounded ostiole when growing on PDA (Hyde 1995c). Based on these observations, Hyde (1995c) concluded that the ascoma morphology, in particular the ostiolar shape, is highly influenced by the substratum, corroborating the suggestions of previous workers (Holm and Holm 1988).

The sample of Massarina species studied includes species without any ascospore sheath ( $M$. corticola), species with sheaths following the outline of the ascospores (M. eburnea, M. thalassiae, and M. walkeri), species with sheaths with appendages (M. armatispo$r a, M$. bipolaris, and $M$. fronsisubmersa) and species with a sheath that expands when the membrane is ruptured (M. ramunculicola). Results from our phy- 
logenetic analysis do not indicate an early divergence of these characters; they may be evolutionarily convergent. Mucilaginous spore sheaths are presumably associated with attachment to substrates and dispersal of spores, and are hence highly influenced by environmental factors, in particular by whether the habitat is terrestrial or aquatic.

Our data support the idea that species of Massarina with broad, ellipsoidal ascospores, together with M. eburnea, should remain in Massarina sensu stricto. Species with narrow, fusiform ascospores must be incorporated into the genus Lophiostoma, a large genus which warrants a thorough review. The genus Vaginatispora K.D. Hyde was introduced to describe $V$. aquatica, which differs from Massarina in morphology of the ascoma and neck, and in particular the ascospore sheath (Hyde 1995c). In ascospores of $V$. aquatica, the central septum is surrounded by a mucilaginous collar, which is continuous with a spreading mucilaginous sheath. This genus, Vaginatispora, with similar morphology to both Massarina and Lophiostoma, needs to be further investigated.

Massarina walkeri was first described by Shoemaker et al (1991) to describe the teleomorph of Acrocalymma medicaginis, which is parasitic on alfalfa (Medicago sativa). Aptroot (1998) in his world revision of Massarina, noted that this species is only doubtfully included into the genus, as it shares many characters with Leptosphaeria Ces. \& De Not. (Shoemaker et al 1991). In addition, the associated anamorph is morphologically dissimilar to the other more commonly reported anamorphs of Massarina (Aptroot 1998). Massarina walkeri should be excluded from Massarina, but whether it represents a separate genus or fits an existing genus remains to be determined.

Massarina papulosa (Durieu \& Mont.) Bose was recently excluded from Massarina and the new genus and species Oletheriostrigula papulosa (Durieu \& Mont.) S.M. Huhndorf \& R.C. Harris (Huhndorf and Harris 1996) was introduced. Oletheriostrigula papulosa fits within the circumscription of Massarina in its immersed ascomata and in the color of its ascospores, but differs in having thick-walled asci with a much thicker apex and consistently 4-septate ascospores with a thickened outer wall. Moreover, true apically free paraphyses are present and persistent in the mature ascomata. This species is deviant within Massarina, and our molecular data confirm that it must be excluded.

Species of Massarina are found in diverse habitats in nature. Lophiostoma species, while mainly terrestrial (Chesters and Bell 1970, Holm and Holm 1988), are also known from aquatic environments (Hyde and Aptroot 1998, Shearer 1993). The Massarina and Lophiostoma species studied here were selected on the basis of morphological diversity and from different habitats: terrestrial (M. eburnea, M. corticola, $M$. walkeri and all species of Lophiostoma), freshwater (M. bipolaris, M. fronsisubmersa, and Vaginatispora aquatica) and marine or intertidal ( $M$. armatispora, M. thalassiae, and M. ramunculicola). It has been previously suggested that the broadly defined Ingoldian ascomycetes originated from various terrestrial counterparts (Shearer 1993, Ranghoo et al 2000). Spatafora et al (1998) have shown that the halosphaerialean ascomycetes also evolved more than once independently from terrestrial ancestors. Our data reveal close relationships between terrestrial and aquatic species of Massarina and Lophiostoma, and the proposed terrestrial origin of the aquatic species is supported.

\section{TAXONOMY}

Based on the combined results of a morphological taxonomic study of all available types of described Massarina species (Aptroot 1998) and the phylogenetic trees of selected species presented here, we propose to maintain in the genus Massarina species in this study with broadly fusiform to ellipsoidal spores (as in the type species, M. eburnea).

The 5 species in this study with fusiform spores, previously undoubtedly placed in Massarina, are herewith transferred into Lophiostoma, thus widening the circumscription of Lophiostoma to encompass not only taxa with slot-like ostioles, but also with punctiform ostioles. We expect other Massarina species with narrowly fusiform or fusiform spores to be similarly disposed, but molecular evidence is required before any transfer of these is made.

Although not all described species currently placed in Lophiostoma have been studied by us, we do not hesitate to provide the necessary new combinations, because no extant species now classified in Lophiostoma or Lophiotrema have punctiform ostioles. Some ascomata in specimens with mainly slot-like ostioles, however, are reported to possess punctiform 'reduced' ostioles. The shape of the ostiole still provides a useful and constant species character, but does not warrant a generic distinction. Three species accepted in Massarina have slot-like ostioles (Aptroot 1998). They were classified in Massarina rather than in $\mathrm{Lo}$ phiostoma because they lack the 'lophiostomoid' (Holm and Holm 1988) peridium structure typical for the type and some other species of Lophiostoma. However, this peridial structure is very variable in its expression (probably resulting from the interaction with bark and wood of the host), even within a single specimen, and cannot therefore be regarded as a useful character, not even at specific level. 
The second and third authors have examined type specimens for all taxa cited below, so as to ascertain the identity of the application of the names. None are regarded synonymous either.

Lophiostoma armatisporum (K.D. Hyde, Vrijmoed, Chinnaraj \& E.B.G. Jones) Liew, Aptroot \& K.D. Hyde comb. nov.; basionym: Massarina armatispora K.D. Hyde, Vrijmoed, Chinnaraj \& E.B.G. Jones, Bot. Mar. 35: 325. 1992.

Lophiostoma bipolare (K.D. Hyde) Liew, Aptroot \& K.D. Hyde comb. nov.; basionym: Massarina bipolaris K.D. Hyde, Nova Hedwigia 61: 131. 1995.

Lophiostoma corticolum (Fuckel) Liew, Aptroot \& K.D. Hyde comb. nov.; basionym: Trematosphaeria corticola Fuckel, Jahrb. Nassauischen Vereins Naturk. 23-24: 162. 1870 ['1869'].

Lophiostoma frondisubmersum (K.D. Hyde) Liew, Aptroot \& K.D. Hyde comb. nov.; basionym: Massarina fronsisubmersa K.D. Hyde, Mycol. Res. 98: 724. 1994.

Lophiostoma rubi (Fuckel) Liew, Aptroot \& K.D. Hyde comb. nov.; basionym: Massaria rubi Fuckel, Jahrb. Nassauischen Vereins Naturk. 25-26: 303. 1871.

\section{ACKNOWLEDGMENTS}

This research was funded by The Hong Kong Research Grants Council. E.C.Y. Liew thanks the University of Hong Kong for a Post-Doctoral Research Fellowship. The technical assistance of V.M. Ranghoo and D. Alex is gratefully acknowledged. Dr R.C. Summerbell is warmly thanked for critically reading the text.

\section{LITERATURE CITED}

Aptroot A. 1998. A world revision of Massarina (Ascomycota). Nova Hedwigia 66:89-162.

—, Fröhlich J, Hyde KD. 2000. Fungi from palms. XLIV. Two new Massarina species with pigmented ostioles. Nova Hedwigia 70:227-232.

Arx JA von, Müller E. 1975. A re-evaluation of the bitunicate Ascomycetes with keys to the families and genera. Studies in Mycol 9:1-159.

Barr ME. 1987. Prodromus to class Loculoascomycetes. Massachusetts: M. E. Barr Bigelow. 168 p.

- 1992. Notes on Lophiostomataceae (Pleosporales). Mycotaxon 45:191-221.

Bose SK. 1961. Studies on Massarina Sacc. and related genera. Phytopatologische Zeitschrift 41:151-213.

Chesters CGC, Bell A. 1970. Studies in the Lophiostomataceae Sacc. Mycol Papers 120:1-55.

Clements FE, Shear CL. 1957. The genera of fungi. New York: Hafner. 496 p.

Cunningham CW. 1997. Is congruence between data partitions a predictor of phylogenetic accuracy? Empirically testing an iterative procedure for choosing among phylogenetic methods. Syst Biol 46:464-478.

Eriksson O. 1981. The families of bitunicate ascomycetes. Op Bot 60:1-209.
1982. Outline of the ascomycetes-1982. Mycotaxon 15:203-248.

- Hawksworth DL. 1985. Outline of the ascomycetes-1985. Syst Asco 4:1-79.

—, Yue JZ. 1986. Bertiella (Sacc.) Sacc. \& Sydow. A synonym of Massarina Sacc. Mycotaxon 27:247-253.

Felsenstein J. 1984. Distance methods for inferring phylogenies: a justification. Evolution 38:16-24.

Gilbert D. 1998. SeqPup ver. 0.8. Indiana University, Bloomingdale.

Hasegawa M, Kishino H, Yano T. 1985. Dating the humanape split by a molecular clock of mitochondrial DNA. J Mol Evol 22:160-174.

Holm L, Holm K. 1988. Studies in the Lophiostomataceae with emphasis on the Swedish species. Symb Bot Upsal 28:1-50.

Huhndorf SM, Harris RC. 1996. Oletheriostrigula, a new genus for Massarina papulosa (Fungi, Ascomycetes). Brittonia 48:551-555.

Hyde KD. 1989. Intertidal fungi from the mangrove fern, Acrostichum speciosum, including Massarina acrostichi sp. nov. Mycol Res 93:435-438.

- 1991. Massarina velatospora and a new mangroveinhabiting species, M. ramunculicola sp. nov. Mycologia 83:839-845.

- 1992. Tropical Australian freshwater fungi. I. Some ascomycetes. Austral Syst Bot 5:109-116.

-1994. Aquatic fungi on rachides of Livistona in the Western Province of Papua New Guinea. Mycol Res 98: 719-140.

1995a. The genus Massarina, with a description of M. eburnea and an annotated list of Massarina names. Mycol Res 99:291-296.

1995b. Tropical Australian freshwater fungi. VII. New genera and species of Ascomycetes. Nova Hedwigia $62: 119-140$.

__- 1995c. Tropical Australian freshwater fungi. IX.Vaginatispora aquatica gen. et sp. nov. Nova Hedwigia 61:233-241.

—, Aptroot A. 1997. Fungi from palms. XXXIII. The genus Massarina, with a new species. Nova Hedwigia 64:491-504.

- Aptroot A. 1998. Tropical freshwater species of the genera Massarina and Lophiostoma (ascomycetes). Nova Hedwigia 66:489-502.

— Borse BD. 1986. Marine fungi from Seychelles. VI. Massarina velataspora, a new marine ascomycotina from mangrove wood. Mycotaxon 27:161-167.

— sarina armatispora $\mathrm{sp}$. Nov., a new intertidal ascomycete from mangroves. Botanica Marina 35:325-328.

Jukes TH, Cantor CR. 1969. Evolution of protein molecules. In: Munro HN, ed. Mammalian protein metabolism. New York: Academic Press. p 21-132.

Kimura M. 1980. A simple method for estimating evolutionary rate of base substitutions through comparative studies of nucleotide sequence. J Mol Evol 16:111-120.

Kishino H, Hasegawa M. 1989. Evaluation of the maximum likelihood estimate of the evolutionary tree topologies 
from DNA sequence data, and the branching order of Hominoidea. J Mol Evol 29:170-179.

Kohlmeyer J, Volkmann-Kohlmeyer B. 1987. Marine fungi from Aldabra, the Galapagos, and other tropical islands. Can J Bot 65:571-582.

Liew ECY, Hyde KD, Aptroot A. 2000. Phylogenetic significance of the pseudoparaphyses in loculoascomycete taxonomy. Mol Phylog and Evol 16:392-402.

Luttrell ES. 1973. Loculoascomycetes. In: Ainsworth GC, Sparrow FK, Sussman AS, eds. The Fungi, an advanced treatise. New York: Academic Press. p 135-219.

Müller E, Arx JA von. 1962. Die Gattungen der didymosporen Pyrenomyceten. Beitr. Kryptogamenfl. Schweiz 11:1-922.

Munk A. 1956. On Metasphaeria coccodes (Karst.) Sacc. and other fungi probably related to Massarina Sacc. (Massarinaceae n. fam.). Friesia 5:303-308.

Poonyth AD, Hyde KD, Aptroot A, Peerally A. 1999. Three new species of Massarina associated with terrestrial, non-marine parts of mangroves. Fungal Diversity 3: 139-146.

Ranghoo VM, Hyde KD, Liew ECY. 2000. Molecular techniques and phylogeny. In: Hyde $\mathrm{KD}$, Pointing $\mathrm{SB}$, eds. Marine mycology: a practical approach. Fungal Research Series 1. Hong Kong: Fungal Diversity Press. $p$ 308-336.

Read SJ, Jones EBG, Moss ST. 1997. Ultrastructural observations of asci, ascospores and appendages of Massarina armatispora (Ascomycota). Mycoscience 38:141146.

—- Moss ST, Jones EBG. 1994. Ultrastructure of asci and ascospore sheath of Massarina thalassiae (Loculoascomycetes, Ascomycota). Botanica Marina 37:547553.

Saccardo PA. 1883. Sylloge Fungorum 2:1-813.

Scheinpflug H. 1958. Untersuchungen über die Gattung $D i$ - dymosphaeria Fuck. un einige verwandte Gattungen. Ber. Schweiz. Bot. Ges. 68:325-383.

Shearer CA. 1993. The freshwater ascomycetes. Nova Hedwigia 56:1-33.

- Hyde KD. 1997. Massarina ingoldiana, a new ascomycete from freshwater habitats. Mycologia 89:114119.

Shoemaker RA, Babcock CE, Irwin JAG. 1991. Massarina walkeri n.sp., the teleomorph of Acrocalymma medicaginis from Medicago sativa contrasted with Leptosphaeria pratensis, $L$. weimeri n.sp., and L. viridella. Can J Bot 69:569-573.

Spatafora JW, Volkmann-Kohlmeyer B, Kohlmeyer J. 1998. Independent terrestrial origins of the Halosphaeriales (Marine Ascomycota). Am J Bot 85:1569-1580.

Srinivasulu BV, Sathe PG. 1974. Genus Massarina from India. Sydowia 26:83-86.

Swofford DL. 1998. PAUP*. Phylogenetic analysis using parsimony (*and other methods). Version 4. Massachusetts: Sinauer Associates.

Thompson JD, Higgins DJ, Gibson TJ. 1994. CLUSTAL W: improving the sensitivity of progressive multiple sequence alignment through sequence weighting, position specific gap penalties and weight matrix choice. Nucl Acids Res 22:4673-4680.

Tsui KM, Hyde KD, Hodgkiss IJ. 1999a. Massarina proprietunicata sp. nov., from submerged wood in streams in Hong Kong. Mycol Res 103:1575-1578.

-, Wong SW, Hyde KD, Hodgkiss IJ. 1999b. Ultrastructural studies of Massarina ingoldiana and M. purpurascens. Mycologia 91:721-726.

White TJ, Bruns T, Lee S, Taylor J. 1990. Amplification and direct sequencing of fungal ribosomal RNA genes for phylogenetics. In: Innis MA, Gelfand DH, Sninsky JJ, White TJ, eds. PCR protocols: a guide to methods and applications. California, San Diego: Academic Press. p 315-322. 